Review Article

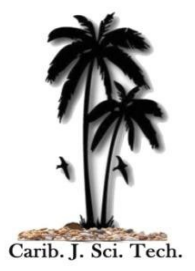

$\underline{\text { Authors \& Affiliation }}$

C Shreya,

M. Albert Gnana Prasad, Chandra Bala Sekharan*

Department of Life Sciences, Lalaji Memorial Omega International School, Chennai, Tamilnadu - 600128, India

Corresponding Author

Chandra Bala Sekharan

Email id:

chandrabala.sekharan@omegaschools.org

Received $30^{\text {th }}$ Dec'2021,

Accepted $2^{\text {nd }}$ Jan' 2022

(C) 2021. The Authors. Published under

Caribbean Journal of Science and Technology

ISSN 0799-3757

\section{Covid19 and its vaccines}

\begin{abstract}
After the outbreak of covid19 (SARS-CoV-2) which comes under the group of coronaviruses, the whole world has been shut down, lockdown being imposed in several countries, death rates rising, people suffering lack of hospitals with treatment related to covid, lack of medicine like remedisivir, etc., lack of beds in the hospitals and what more. The first case of covid19 was observed in Wuhan city of central China at the end of December 2019. Every person on this earth has been impacted one way or the other due to this pandemic. Wearing masks and carrying hand sanitizers has become a regular custom these days. Initially, it was very difficult for the people to cope up with the new normal but after understanding the importance of rules and the severity of covid 19 people started getting used to the new normal. The world is working together to combat this pandemic and now with high difficulties, various pharmaceutical companies have come up with vaccines against covid19. The availability of vaccines varies from one country to another. Thus, now it is the responsibility of the people to get vaccinatedas they break the chain of spread and we can get back our normal lives. This article reviews the coronavirus in general and talks about the impact of livelihood in this pandemic and a few of the vaccines available in the market which has been authorized and approved for the people to get vaccinated.
\end{abstract}

Keywords: Covid19; Coronavirus; Remedesivir; Vaccines.

\section{Introduction}

A virus is a perfect and small parasite that requires a host cell to undergo self-reproduction and replication which will take place only in the cells of living organisms ${ }^{1}$. If entered into a vulnerable host cell, viruses seize over their cellular processes instead they produce virally ciphered proteins that will replicate the virus's genetic material to produce more of their kind. It is a part of the viral mechanisms to translocate the genetic materials and the proteins to congregate them into new viral particles. A virion which is the complete individual viral particle has a very simple structure when compared to that of a bacterium. a virion includes a genome consisting of a few particles of either DNA or RNA, which is again surrounded by a protein coat called capsid. Many viruses have an extra outer membrane that bound the capsid and so they are called enveloped viruses ${ }^{2}$. This envelope comes from the infected host cells 
from the small segments of the cell's plasma membrane, the envelope may then play a major role in helping the newly formed virus particles to survive and infect the cells. So now it will be easier to relate to how coronaviruses spread within our bodies.

\section{Coronavirus}

Coronaviruses originate from the virus family Coronaviridae. It is one of the largest known RNA viruses, with a genome size of $31 \mathrm{~kb}$. Coronavirus has expanded its host range in recent times, they infect a wide range of mammalian hosts but the key point that has to be highlighted here is that the risk of animals spreading coronavirus is marginally small, indeed the severe acute respiratory syndrome- coronavirus 2 may have been originated from bats but it's way into and spread within humans is unknown ${ }^{2}$. Known human coronaviruses are associated with mild respiratory disease. High mutation rates play a major role in host range expansion. In specific RNA, viruses intrinsically have a higher mutation rate when compared to DNA viruses. High mutation rates lead virus populations to produce higher levels of genetic variations which in turn leads to disease progression. Although coronaviruses undergo evolution by mutating themselves, it is also essential to consider the host genetic factors which lead to genetic variation, for considering in the good books we could also highlight the fact that Genetic variation is a prerequisite for biological evolution ${ }^{3}$. Transmission of coronavirus takes place through airborne droplets ${ }^{4}$ and it causes severe infection and damage at the infected site. There were six types of human coronaviruses out of which one of the species subdivided itself into two different strains, thus making the total number of species seven. They are

- $229 \mathrm{E}(\alpha)$

- $\quad \mathrm{NL63}(\alpha)$

- $\mathrm{OC} 43(\beta)$

- $\operatorname{HKU1}(\beta)$

- MERS-CoV, a $\beta$ virus that triggermiddle east respiratory syndrome

- $\quad$ SARS-CoV, a $\beta$ virus that trigger severe acute respiratory syndrome

- $\quad$ SARS-CoV-2, which triggerCOVID-19.
When it comes to symptoms the most common symptoms of coronaviruses are fever, cold, cough, breathlessness, and gastrointestinal symptoms which include diarrhea, nausea, vomiting. It is significant to note that patients with gastrointestinal symptoms suffered from a longer duration of symptoms than patients without gastrointestinal symptoms ${ }^{5}$. Further human coronaviruses are divided into low pathogenic and high pathogenic coronaviruses. The low pathogenic coronaviruses affect the upper respiratory tract and it causes mild infections and respiratory illnesses whereas high pathogenic coronaviruses infect the lower airways and lungs severely and it may lead to fatal pneumonia and other serious illnesses, examples of high pathogenic coronaviruses are severe acute respiratory syndrome coronaviruses (SARS-CoV) and middle east respiratory coronaviruses (MERS-CoV) ${ }^{6}$. Thus, we can say that high pathogenic coronaviruses are a considerable threat to humans.

\section{Covid19}

COVID19 is yet another infectious disease that is caused by a newly discovered Coronavirus. (SARSCoV2) which is again a different strain of SARSCOV. The major symptoms are loss of taste and smell, fever, cold, cough, breathlessness, headache, and tiredness ${ }^{7}$.

\section{Effect On the Livelihood}

All the people have been affected either financially, mentally, or health-wise in this pandemic due to covid $19^{8}$. The uncertain nature and the spread of the covid19 are making it extremely difficult for governments across the world to formulate rules and policies to control the spread of covid19. Several countries were under lockdown and this, in turn, affected the economic conditions of different countries worldwide. There is a big hit to a huge number of small jobs and upcoming enterprises in our society. Several people lost their jobs due to this pandemic. There was a lot of pressure on governments and all the governments across the country were forced to take decisions fast rather than analyzing and researching the outcomes possible ${ }^{9}$. It was more like a do-or-die situation for the governments of various countries across the world. The death rate increased and as the cases became inevitable day by day, there was a shortage of beds 
and other equipment needed for a patient suffering from covid19. this made it a necessity for the rapid development of a vaccine against coronavirus ${ }^{10,11}$. Thus safe effective covid vaccines were created by scientists in response to this serious global pandemic by the world's unleashing biomedical and pharmaceutical companies and surprisingly it is among the fastest vaccines to be found in our history ${ }^{12}$.

\section{Vaccines}

Prioritizing the finding of a vaccine for covid19 was the most significant job, and a lot of effort has been put on the same too ${ }^{13}$. Here are some of the few common vaccines available in the market for covid19

- PFIZER AND BIONTECH

- astrazENECA

- covaxin

- MODERNA

- NOVAVAX

\section{Pfizer and Biontech}

This vaccine was the world's first approved vaccine. It is one of the common covid19 vaccines manufactured by Pfizer, Inc, and BioNTech in the countries the USA, Germany. The general name of this vaccine is Pfizer and BioNTech vaccine and its generic name is Tozinameran. Its type is mRNA BNT162b2 and this technique has been new in vaccine manufacture it was difficult to predict its consequences, a minor to moderate side effects of this vaccine were observed ${ }^{14,15}$. The effectiveness of this vaccine has been $95 \%$ on preventing covid 19 . When it comes to the transportation and distribution of this vaccine, it is complicated particularly in countries of low income and hot climate. To throw light on how this particular vaccine functions, we have to consider that this particular vaccine is contrived of the particles of lipids which bestow RNA into the host cells which lead to the expression of the SARS-CoV-2 S antigen and now this induces an immune response to the $\mathrm{S}$ antigen, which protects us from covid19 ${ }^{16}$. It consists of 2 doses which should be taken at least 21 days apart. The authorization of the Pfizer vaccine was on December $11,2020^{17}$ and it has given an ultimate fight for the covid19.

\section{Moderna}

One of the common vaccines produced then the USA. The general name is the Moderna vaccine ${ }^{18}$ and its generic name is the Moderna covid19 vaccine ${ }^{19}$. It is manufactured by ModernaTX, Inc. its type is mRNA-1273. When it comes to its effectiveness it is $94.5 \%$ effective in preventing the covid 19 vaccine ${ }^{13}$. It should be taken in 2 dosages and each dosage must be taken with a gap of 28 days. Transportation and distribution are difficult in countries of low income and hot climates. When it comes to the working of this particular vaccine, we can highlight that it is formulated through lipid particles and this is a nucleoside-modified mRNA vaccine. The lipid particles induce the nucleoside modified mRNA into the host cells to allow expression of the SARS-CoV$2 \mathrm{~S}$ antigen. This vaccine provides an immune response to the $\mathrm{S}$ antigen, which protects the hosts against COVID-19. These antibodies that have been induced are specific to the SARS-CoV-2 virus to protect against future infections. Following the first dose, the analytical symptoms were limited which includes fever, redness, and swelling on the area vaccinated headache, and fatigue but after the second dose it was from moderate to severe and this includes facial swelling too ${ }^{20}$. this vaccine was authorized on December 18, 2020.

\section{Covaxin}

India is the second highly populated country which one of the world's biggest manufacturing companies thus India had a crucial role to come out with a vaccine as soon as possible. Covaxin was developed by an Indian company Bharat biotech covaxin comes in a 2 dosage regimen which should be taken with a gap of 28 days. Its type is inactivated virus. This vaccine has been made more suitable for the Indian climate ${ }^{21}$. When it comes to its effectiveness, coxaxin is $70-80 \%$ effective in preventing covid19. Quite a good number of covaxins are also donated to various underdeveloped countries proving the good gesture ${ }^{22}$. As covaxin is an inactivated virus, it enhances the antibody response as it is a dead cell where the basic genetic material, RNA and DNA has been destroyed and so this cell has no chance to replicate or infect inside the body $^{23}$. Thus, it is completely safe. 


\section{AstraZeneca}

It was manufactured by pharmaceutical companies in UK, Sweden, India and was approved in March 2021. This should also be taken in 2 dosages with a minimum of 84 days gap between each dose. When it comes to the effectiveness, it is $70-90 \%$ effective in preventing covid19. It is a chimpanzee adenovirus vectored vaccine ${ }^{24}$. It is approved by more than 130 countries across the world. Minimal and rare cases of blood clots were reported after getting vaccinated in $\mathrm{UK}^{25,26}$. Its distribution worldwide is mainly due to the reason that it does not need cold chain management which is very much required for Pfizer-BioNTech vaccine and Moderna vaccine and it is more affordable ${ }^{27}$.

\section{Novavax}

Novavax is a protein-based and virus-like particle covid19 vaccine produced by the US Biotechnology company Novavax. It should be taken in 2 dosages with a gap of 28 days. Its efficacy ranges from 85 $90 \%{ }^{28}$. This vaccine leads to antibody neutralization titers in all patients. The vaccine is stable at 2-8 degrees Celsius, refrigerated temperatures ${ }^{29}$. The side effects of novavax are mild mostly being pain at the site of injection, fatigue, headache, and tenderness ${ }^{30}$. When it comes to storage and transportation novavax is easy to store and transport. This vaccine with a high efficacy rate is considered a major breakthrough in many developed countries which needed more doses to vaccinate its people as soon as possible ${ }^{31,32}$.

\section{Conclusion}

It is not necessary to choose a vaccine that is the best and wait for it till it is available in your respective countries. one should remember that every vaccine has its advantages and disadvantages and every vaccine is available for individuals after various clinical trials safety measures. All the approved vaccines are safe and to break the spread of coronavirus, everyone needs to get vaccinated. It is always wise to follow the saying that prevention is better than cure. No one can assure you that after getting vaccinated there is no chance of being affected by covid19 but all they say is that the severity of the disease will be reduced. Let us get back to normal by getting proudly vaccinated.

\section{Conflict of interest}

This work has no conflict of interest.

\section{References}

1. Nihala, N.C.H.; Sheeba, P.; Honey, S. Corona viruses: A review on SARS, MERS and COVID-19. Microbiol. Insights, 2021, 14, 110. DOI:10.1177/11786361211002481.

2. Jianzhong, S.; Zhiyuan, W.; Gongxun, Z.; Huanliang, Y.; Chong, W.; Baoying, H. Susceptibility of ferrets cats dogs and other domesticated animals to SARS - coronavirus 2. Science, 2020, 368 (6494), 1016-1020. DOI:10.1126/science.abb7015

3. Kohei, F.; Kazuma, U. Genetic variation in human severe acute respiratory syndrome coronavirus receptor ACE2 and serine protease TMPRSS2. J. Clin. Pathol., 2021, 74 (5), 307-313. DOI:10.1136/jclinpath-2020206867.

4. Dharmendra, K.;Rishabha, M.; Pramod, K.S. Corona Virus: A Review of COVID19. Eurasian J. Med. Oncol., 2020, 4(1), 825. DOI:10.14744/ejmo.2020.51418.

5. Nobel, Y.R.; Phipps, M.; Zucker, J.; Lebwohl, B.; Wang, T.C.; Sobieszczyk, M.E.; Freedberg, D.E. Gastrointestinal symptoms and coronavirus disease 2019: A case-control study from the United States. Gastroenterology, 2020, 159(1), 373-375.e2. DOI:10.1053/j.gastro.2020.04.017.

6. Roudragouda, C.; Stanley, P. Pathogenic human coronavirus infections: causes and consequences of cytokine storm and immunopathology. Semin. Immunopathol., 2017, 39(5), 529-539. DOI:10.1007/s00281017-0629-x.

7. Tomasz, D.; Lukasz, S.; Krzysztof, J.F.; Milosz, J.; Jerzy, R.L.; Jacek, S. COVID-19 challenge for modern medicine. Cardiol. J., 2020, 27(2), 175-183. DOI:10.5603/ CJ.a2020.0055.

8. Gagan, D.S.; Mandeep, M. Lives or livelihood: Insights from locked-down India due to COVID19.Soc. Sci. Human. Open., 2020, 2(1), 100036. DOI: 10.1016/j.ssaho. 2020.100036 .

9. Warwick, M.; Roshen, F. The global macroeconomic impacts of COVID-19: Seven 
Scenarios.Asian Econ. Pap., 2021, 20(2), 130. DOI:10.1162/asep_a_00796.

10. Barney, S.G. Rapid COVID-19 vaccine development. Science, 2020, 368 (6494), 945946. DOI:10.1126/science.abb8923

11. Sarah, K.B.; Judy, A.B.; Jeffrey, N.R. Summary of the vaccines and related biological products advisory committee meeting held to consider evaluation of vaccine candidates for the prevention of respiratory syncytial virus disease in RSV-naïve infants. Vaccine, 2020, 38(2), 101-106. DOI: 10.1016/ j.vaccine.2019.10.048.

12. Wang, C.; Wang, Z.; Wang, G. COVID-19 in early 2021: current status and looking forward. Signal Transduct. Target. Ther., 2021, 6, 114. DOI:41392-021-00527-1.

13. Vashishtha, V.M.; Kumar, P. Development of SARS-CoV-2 vaccines: challenges, risks, and the way forward. Hum. Vaccin. Immunother., 2020, 17 (6), 1635-1649. DOI: 10.1080/ 21645515.2020 .1845524$.

14. Tomasz, D.; Lukasz, S.; Krzysztof, J.F.; Milosz, J.; Jerzy, R.L.; Jacek, S. COVID-19 challenge for modern medicine. Cardiol. J., 2020, 27(2), 175-183. DOI:10.5603/ CJ.a2020.0055.

15. El-Shitany, N.A.; Harakeh, S.; Badr-Eldin, S.M.; Bagher, A.M.; Eid, B.; Almukadi, H.; Alghamdi, B.S.; Alahmadi, A.A.; Hassan, N.A.; Sindi, N.; Alghamdi, S.A.; Almohaimeed, H.M.; Mohammedsaleh, Z.M.; Al-Shaikh, T.M.; Almuhayawi, M.S.; Ali, S.S.; El-Hamamsy, M. Minor to Moderate Side Effects of Pfizer-BioNTech COVID-19 Vaccine Among Saudi Residents: A Retrospective Cross-Sectional Study. Int. J. Gen. Med., 2021, 14, 1389-1401. DOI:10.2147/IJGM.S310497.

16. Anderson, E.J.; Rouphael, N.G.;Widge, A.T.; Jackson, L.A.; Roberts, P.C.;Makhene, M.; Chappell, J.D.; Denison, M.R.; Stevens, L.J.; Pruijssers, A.J. mRNA1273 Study Group. Safety and Immunogenicity of SARS-CoV-2 mRNA-1273 Vaccine in Older Adults. New Eng. J. Med., 2020, 383,2427-2438.

17. Widge, A.T.; Rouphael, N.G.; Jackson, L.A.; Anderson, E.J.; Roberts, P.C.; Makhene, M.;
Chappell, J.D.; Denison, M.R.; Stevens, L.J.; Pruijssers, A.J.mRNA-1273 study group. Durability of responses after SARSCoV-2 mRNA-1273 vaccination. New Eng. J. Med., 2021, 384, 80-82.

18. Kamala, T. Covid-19: India is at centre of global vaccine manufacturing, but opacity threatens public trust. The $B M J, \mathbf{2 0 2 1}, 372$, n196. DOI:10.1136/bmj.n196.

19. Ledford, H. Moderna COVID vaccine becomes second to get US authorization. Nature, 2020, Dec 18. DOI:10.1038/d41586020-03593-7.

20. Meo, S.A.; Bukhari, I.A.; Akram, J.; Meo, A.S.; Lonoff, D.C.K. COVID-19 vaccines: comparison of biological, pharmacological characteristics and adverse effects of Pfizer/BioNTech and Moderna vaccines. Eur. Rev. Med. Pharmacol. Sci., 2021, 25, 16631669.

21. Kamala, T. What do we know about India's Covaxinvaccine?. The BMJ, 2021, 21, 373, n997. DOI:10.1136/bmj.n997.

22. Kamala, T. Covid-19: India is at centre of global vaccine manufacturing, but opacity threatens public trust. The $B M J, \mathbf{2 0 2 1}, 372$, n196. DOI:10.1136/bmj.n196.

23. Heena, B.C.; Indra, H.S.; Yash, R.B.; Priyanka, R.B.; Rohan, R.P. COVID-19 Vaccines: Systematic review. World J.Advan. Res. Rev., 2021, 10(01), 143-155. DOI:10.30574/wjarr.2021.10.1.0118.

24. Maria, D.K.; Chizoba, W. Oxford AstraZeneca covid19. Lancet, 2021, 397(10269), 72-74. DOI:10.1016/S01406736(20)32623-4.

25. Diksha, K.; Bishun, D.P.; Padmanabh, D.; Sangita, S. COVID-19 Vaccines: A possible solution to the ongoing pandemic. The Pharm. Innov., 2021, 10(5), 1142-1145.

26. Jacqui, W. Covid-19: Rare immune response may cause clots after AstraZeneca vaccine, say researchers. The $B M J, \mathbf{2 0 2 1}, 373$, n954. DOI:10.1136/bmj.n954.

27. Samuel, C.; Yeanuk, R.; Henna, R.; Toby, P.; Florence, R.; Rhiannon, O.; Ayolola, E.O.; Rishi, B.; Sabrina, W.; Sarai, K. Who funded the research behind the Oxford-AstraZeneca 
COVID-19 vaccine? Approximating the funding to the University of Oxford for the research and development of the ChAdOx vaccine technology. BMJ Yale, 2021, 2021,125. DOI:10.1101/2021.04.08.21255103.

28. Elisabeth, M. Covid-19: Novavax vaccine efficacy is $86 \%$ against UK variant and $60 \%$ against South African variant. The BMJ, 2021, 372, n296.DOI:10.1136/bmj.n296.

29. Wadman, M.; Jon, C.Novavax vaccine delivers $89 \%$ efficacy against COVID-19 in UK-but is less potent in South Africa. Science, 2021, 2021, Jan 28. DOI:10.1126/science.abg8101.

30. Asher, M. Making way for maternal immunization. Nat. Rev. Drug Discov., 2016, 15(1), 3-4. DOI:10.1038/nrd.2015.38.

31. Jonathan, L.G.; Adam, S.L.; Anna, S.L. SARS-CoV-2 vaccines: a triumph of science and collaboration. JCI Insight., 2020, 6(9), e149187. DOI:10.1172/jci.insight.149187

32. Ravi, V.; Sekharan, C.B.; Hari Babu B. Covid-19 vaccines across the globe-A case study. Carib. J. Sci. Tech., 2021, 9(1), 10-12. 